\title{
SCALING UP INFRASTRUCTURE INVESTMENT IN THE PHILIPPINES ROLE OF PUBLIC-PRIVATE PARTNERSHIP AND ISSUES
}

Stephen Schuster, Joven Balbosa, Christine Tang, Takuji Komatsuzaki, and Shanaka J. Peiris

NO. 13

June 2017
ADB SOUTHEAST ASIA WORKING PAPER SERIES 


\section{ADB Southeast Asia Working Paper Series}

\section{Scaling Up Infrastructure Investment in the Philippines: Role of Public-Private Partnership and Issues}

Stephen Schuster, Joven Balbosa, Christine Tang, Takuji Komatsuzaki, and Shanaka J. Peiris

No. 13 | June 2017
Stephen Schuster, principal financial sector specialist, Public Management, Financial Sector and Trade Division, Southeast Asia Department, Asian Development Bank (ADB)

Joven Balbosa, principal country specialist, Philippines Country Office, ADB

Christine Tang, consultant, ADB

Takuji Komatsuzaki, senior economist, International Monetary Fund (IMF)

Shanaka J. Peiris, IMF Resident Representative to the Philippines. 
(C) 2017 Asian Development Bank

6 ADB Avenue, Mandaluyong City, 1550 Metro Manila, Philippines

Tel +632632 4444; Fax +6326362444

www.adb.org

Some rights reserved. Published in 2017.

Publication Stock No. WPS178887-2

DOI: http://dx.doi.org/10.22617/WPS178887-2

The views expressed in this publication are those of the authors and do not necessarily reflect the views and policies of the Asian Development Bank (ADB) or its Board of Governors or the governments they represent.

ADB does not guarantee the accuracy of the data included in this publication and accepts no responsibility for any consequence of their use. The mention of specific companies or products of manufacturers does not imply that they are endorsed or recommended by ADB in preference to others of a similar nature that are not mentioned.

By making any designation of or reference to a particular territory or geographic area, or by using the term "country" in this document, ADB does not intend to make any judgments as to the legal or other status of any territory or area.

This work is available under the Creative Commons Attribution 3.0 IGO license (CC BY 3.0 IGO)

https://creativecommons.org/licenses/by/3.0/igo/. By using the content of this publication, you agree to be bound by the terms of this license. For attribution, translations, adaptations, and permissions, please read the provisions and terms of use at https://www.adb.org/terms-use\#openaccess

This CC license does not apply to non-ADB copyright materials in this publication. If the material is attributed to another source, please contact the copyright owner or publisher of that source for permission to reproduce it. ADB cannot be held liable for any claims that arise as a result of your use of the material.

Please contact pubsmarketing@adb.org if you have questions or comments with respect to content, or if you wish to obtain copyright permission for your intended use that does not fall within these terms, or for permission to use the ADB logo.

Notes:

In this publication, "\$" refers to US dollars.

Corrigenda to ADB publications may be found at http://www.adb.org/publications/corrigenda 


\section{CONTENTS}

$\begin{array}{lll}\text { TABLES AND FIGURES IV } & \text { IV }\end{array}$

ABBREVIATIONS V V V V V V V

$\begin{array}{ll}\text { I. INTRODUCTION } & 1\end{array}$

II. PUBLIC-PRIVATE PARTNERSHIP PROJECT APPRAISAL AND VALUE FOR MONEY ANALYSIS $\quad 4$

III. GOVERNMENT EXPOSURES UNDER PUBLIC-PRIVATE PARTNERSHIPS $\quad 5$

$\begin{array}{ll}\text { IV. } & \text { PAYMENT GUARANTEES }\end{array}$

$\begin{array}{lll}\text { V. INTERNATIONAL BEST PRACTICES } & 7\end{array}$

$\begin{array}{llr}\text { VI. KEY INSTITUTIONAL ISSUES } & 8\end{array}$

A. Budgeting, Planning, and Project Screening 8

B. Management of Contingent Liabilities 9

C. Accounting Treatment 11

D. Technical Bidding Matters

VII. OTHER INSTITUTIONAL AND LEGAL ISSUES 11

VIII. POLICY RECOMMENDATIONS 13 


\section{TABLES AND FIGURES}

\section{TABLES}

1 Global Infrastructure Competitiveness Ranking of Selected Asian Countries, 2013-2014

2 Risk Allocation for the Daang Hari Road Public-Private Partnership Concession (Build-Transfer-Operate Arrangement)

\section{FIGURES}

1 Investment Funding Requirements for the Philippines, 2013-2017 and Beyond 2

2 ASEAN: Public Investment and Public Capital Stock 2

3 Public-Private Partnership Pipeline Capital Expenditure 3 


\section{ABBREVIATIONS}

$\begin{array}{lll}\text { CLF } & - & \text { Contingent Liability Fund } \\ \text { DOF } & - & \text { Department of Finance } \\ \text { GDP } & - & \text { gross domestic product } \\ \text { GPRAM } & - & \text { generic preferred risk allocation matrix } \\ \text { ICC } & - & \text { Investment Coordination Committee } \\ \text { NEDA } & - & \text { National Economic and Development Authority } \\ \text { PDMF } & - & \text { Project Development and Monitoring Facility } \\ \text { PPP } & - & \text { public-private partnership } \\ \text { VFM } & - & \text { value for money } \\ \text { VGF } & - & \text { viability fund gap }\end{array}$





\section{INTRODUCTION}

1. The Philippine public sector has underinvested in infrastructure for decades. Its public capital stock at 35\% of gross domestic product (GDP) is less than half of the average of member states in the Association of Southeast Asian Nations, and is one of the lowest compared with its peers in the region. The quality of existing facilities is likewise comparatively poor, and consistently ranked low in global surveys of business environment. ${ }^{1}$ Poor infrastructure has also been consistently identified as one of the top three "most problematic factors" in doing business in the Philippines with high attendant economic costs arising from "insufficient capacity relative to demand, poor connectivity, and low quality."

Table 1: Global Infrastructure Competitiveness Ranking of Selected Asian Countries, 2013-2014

\begin{tabular}{|l|c|c|c|c|c|c|}
\hline \multicolumn{1}{|c|}{ Indicator } & Philippines & Singapore & Malaysia & Thailand & Indonesia & Viet Nam \\
\hline Quality of Roads & 87 & 7 & 23 & 42 & 78 & 102 \\
Quality of Railroads & 89 & 10 & 18 & 72 & 44 & 58 \\
Quality of Ports & 116 & 2 & 24 & 56 & 89 & 98 \\
Quality of Airports & 113 & 1 & 20 & 34 & 68 & 92 \\
Quality of Electric Supply & 93 & 8 & 37 & 58 & 89 & 95 \\
Fixed Telephone Connectivity & 109 & 29 & 79 & 96 & 82 & 88 \\
Mobile Telephone Connectivity & 81 & 18 & 27 & 49 & 62 & 21 \\
Overall & 98 & 5 & 25 & 61 & 82 & 110 \\
\hline
\end{tabular}

Source: World Economic Forum (WEF). 2013. The Global Competitiveness Report 2013-2014. Switzerland: WEF. Table take from Corpuz 2040.

2. As such, the country will need to ramp up infrastructure investment to enhance its competitiveness, raise productivity, and sustain the government's targeted $7 \%-8 \%$ economic growth rate over the medium term. To attain the vision, the National Economic and Development Authority (NEDA) launched the Philippine Development Plan, 2017-2022, the first medium-term development plan anchored to the national long-term vision-AmBisyon Natin 2040. Based on the plan, the total funding requirement is P8.4 trillion or $\$ 168$ billion to achieve the targeted infrastructure outlays covering 2017-2022. ${ }^{3}$ Further, NEDA developed a Three-Year Rolling Infrastructure Program (TRIP), which is a modification of the Comprehensive and Integrated Infrastructure Program (CIIP) that serves as a consolidated list of all infrastructure programs of the government, with the TRIP putting more emphasis on immediate priorities to be undertaken in 3-year periods (Figure 1). The TRIP identifies 4,895 projects amounting to P3.6 trillion, all of which have a target completion year of 2020.

3. Public investment infrastructure has remained relatively low in the Philippines recently despite the improved public finances due to weak links between planning and budgeting and slow budget execution. Most of the funding for the infrastructure program is expected to come from government (P4.4 trillion) with the private sector expected to fund close to $\mathrm{P} 2$ trillion or $27 \%$ of the program. ${ }^{4}$ Progress on improving medium term investment planning and budgeting and weak budget execution has been limited and could be further strengthened. The Aquino administration had targeted infrastructure to rise to 5\% of GDP by

1 Takuji Komatsuzaki. 2016. Improving Public Infrastructure in the Philippines. IMF Working Paper Series. No. 16. Washington, DC: International Monetary Fund.

2 Arturo Corpuz. Infrastructure, Urbanization, and the Filipino. Unpublished.

3 Estimates in an ADB study show the same order of magnitudes. For the period 2010-2020, it estimates that the Philippines requires investments in infrastructure of at least $\$ 127.1$ billion. Biswa Nath Bhattacharyay. 2010. Estimating Demand for Infrastructure in Energy, Transport, Telecommunications, Water, and Sanitations in Asia and the Pacific: 2010-2020. ADBI Working Paper Series. No. 248. Tokyo: Asian Development Bank Institute.

4 Footnote 3. 
Figure 1: Investment Funding Requirements for the Philippines, 2013-2017 and Beyond

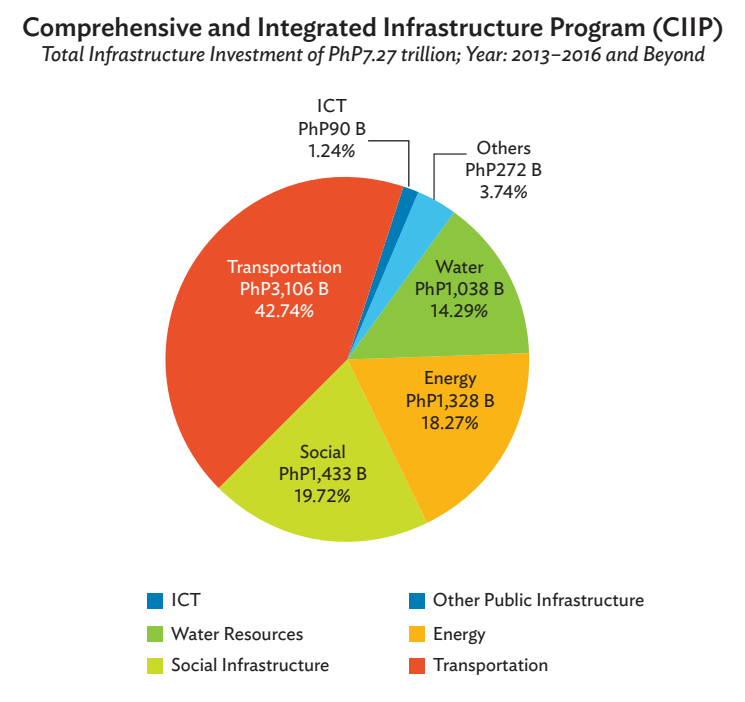
Comprehensive and Integrated Infrastructure Program (CIIP), by Funding Source

Total Infrastructure Investment of PhP7.27 trillion; Year: 2013-2016 and Beyond

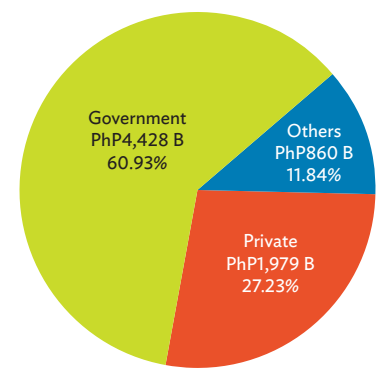

$\square$ ICT

Water Resources Social Infrastructure

Source: NEDA

2016. However, actual spending has consistently fallen short of the target and averaged only about 2.5\% of GDP in 2000-2014, well below that of neighboring Asian countries (Figure 2). ${ }^{5}$ Acknowledging the urgency of raising investments in public infrastructure for sustaining economic growth, the new administration of President Rodrigo Duterte raised the 2017 public infrastructure budget allocation to $5.3 \%$ of GDP with plans to invest up to 7.4\% of GDP by 2022 supported by a comprehensive tax reform package.

\section{Figure 2: ASEAN: Public Investment and Public Capital Stock}

Public Investment

(In percent of GDP)

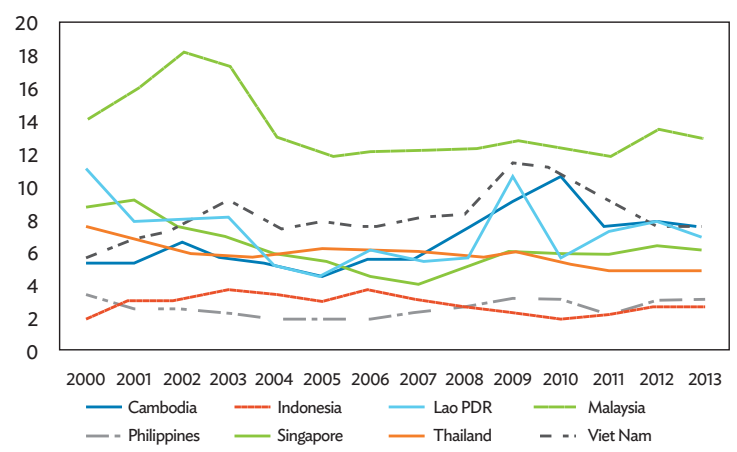

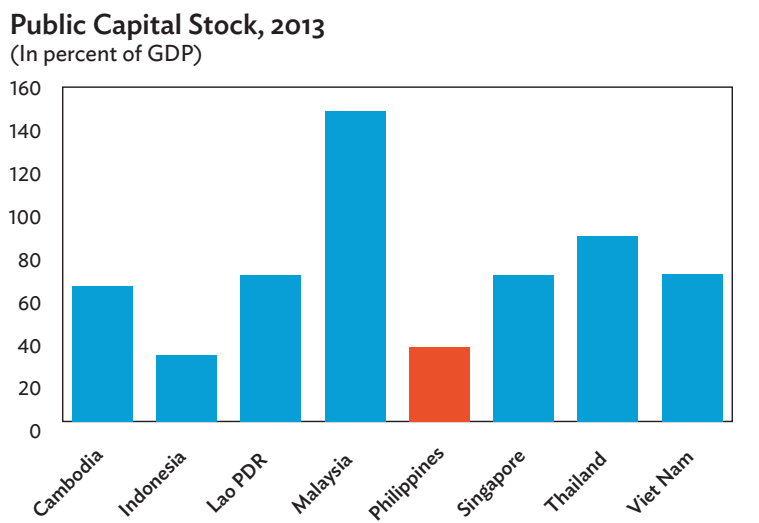

Source: IMF (2015a); and IMF staff estimates.

5 This is in large part a reflection of the bureaucracy's constrained institutional capacity for integrated project planning and implementation, a work in progress that would involve continuous training of government technical staff from the national to the regional and local levels to improve its ability to deliver infrastructure projects (footnote 2). Still, implementation of the budget execution improved in the second half of 2015 and early 2016 reflecting enhanced public finance and procurement management, making the $2 \%$ deficit target of the 2016 budget attainable. 
4. However, the size of the infrastructure need requires the expansion of both budget spending and public-private partnerships (PPP). Therefore, in parallel to direct public spending, there has also been increased emphasis on PPP arrangements as a way for government to tap private sector expertise and resources, and at the same to leverage the limited public budget.

5. The objective of this paper is to outline issues related to the choice between public procurement (including overseas development assistance) and PPPs as well as implementation and monitoring of PPP projects and fiscal risks in general and more specific to the case of the Philippines. The government has been able to steadily strengthen the legal institutional framework for PPP project preparation and approval. In 2014, the Economist Intelligence Unit Infrascope gave the country a score in "PPP readiness" associated with a "developed" PPP market category, moving up from an "emerging" PPP market category in 2011. ${ }^{6}$ Reforms have focused on building institutional capacity to develop, bid out, and approve solicited proposals - supported by technical assistance grants for transactions advisers via a project development and monitoring facility (PDMF) - in line with government's medium-term development plan (For a status check of the government's pipeline PPP projects, see Figure 3). In addition, the PPP Center was reorganized into a more dynamic agency and designated as the central unit for managing PPP projects. This reform ${ }^{7}$ strengthened the project selection and approval processes as well as the risk allocation framework. ${ }^{8}$

Figure 3: Public-Private Partnership Pipeline Capital Expenditure (P Billion)

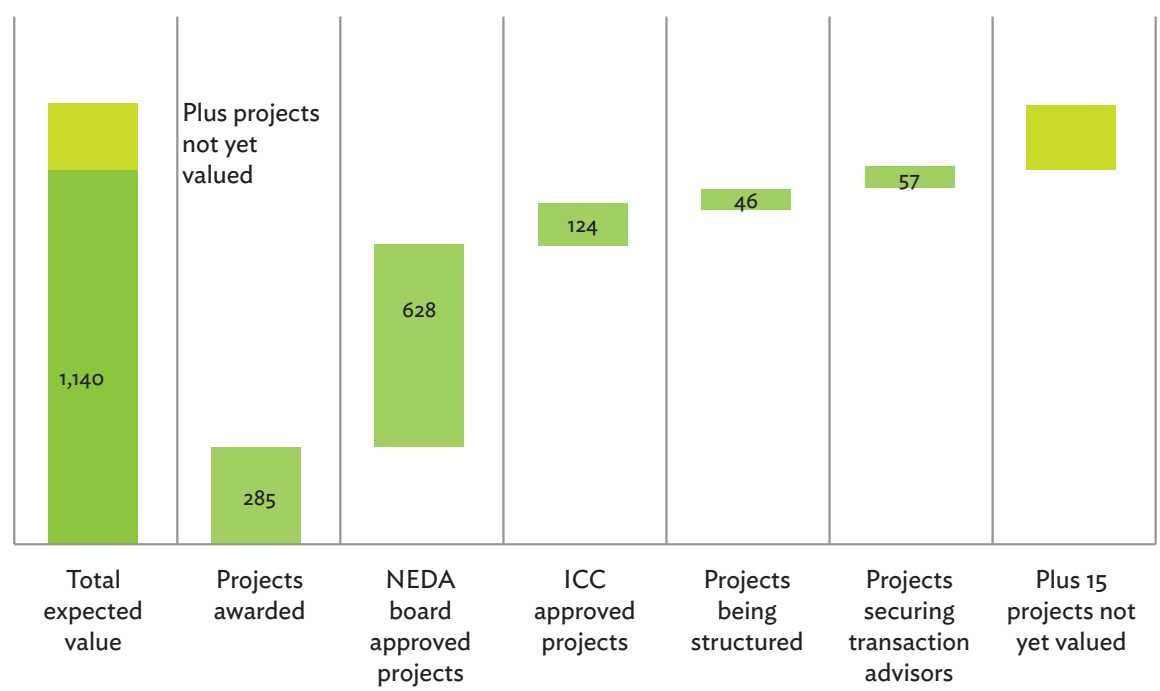

Source: PPP Center, Status of PPP Projects, 15 October 2015.

6 Economist Intelligence Unit. 2015. Evaluating the Environment for Public-Private Partnerships in Asia-Pacific: 2014 Infrascope. London. Cited in Organisation for Economic Co-operation and Development. 2016. Infrastructure Investment in the Philippines. OECD Investment Policy Reviews: Philippines 2016. http://www.keepeek.com/Digital-Asset-Management/ oecd/finance-and-investment/oecd-investment-policy-reviews-philippines-2016/infrastructure-investment-in-thephilippines_9789264254510-10-en\#page26

7 Aziz Haydarov and Vaughn Montes. 2015. Philippines: Guarantees and Contingent Liabilities Review. Policy Paper: Manila: Asian Development Bank.

8 For example, the NEDA ICC has adopted GPRAM, a recommendatory risk allocation guide. Also, specific reforms outlined in various PPP governing board policy circulars include (i) streamlined PPP project appraisal process with definite timelines and defined areas of appraisal; (ii) guidelines for implementing agencies in project identification (use of multicriteria analysis in identifying and selecting PPP projects), risk allocation, and project approval (procedures for project appraisals including use of VFM and principles for using VGF); (iii) protocols for generating, processing, and sharing information on PPP projects; (iv) monitoring responsibilities and protocols; and ( $v$ ) adoption of best practices, including hiring of probity advisors to observe and critic all aspects of procurement processes. 
6. These reforms, and a careful process of learning by doing and market testing have led to the award of 11 projects worth close to $\mathrm{P} 200$ billion, as well as a respectable pipeline of 40 bankable projects ranging from expressways, airports, seaports, water, urban rail, information technology, and social sector projects (i.e., classrooms, hospitals, prisons). ${ }^{9}$ Along with an increased budget, the new administration has also committed to removing bottlenecks in the PPP program to bring in private sector funding for infrastructure.

\section{PUBLIC-PRIVATE PARTNERSHIP PROJECT APPRAISAL AND VALUE FOR MONEY ANALYSIS}

7. Government has put in place a sound PPP project appraisal system (Figure 4). Guidelines on risk allocation are fairly detailed, the assignment of responsibilities for the various aspects of project evaluation is clear, and value for money (VFM) analysis has been included as part of the government's appraisal tools. ${ }^{10}$

8. A critical component of the appraisal system is to assess whether all risks relevant to the project's financial viability have been identified, appropriately allocated, and whether strategies to mitigate risks retained with government have been developed (For a sample risk allocation, see Table 2). This responsibility falls on the Department of Finance (DOF). The Investment Coordination Committee (ICC) has adopted a generic preferred risk allocation matrix (GPRAM) that lists the risk allocation preferences and risk mitigation measures which can be used in the development and implementation of projects. Under the GPRAM, the risks preferred by government include the usual standards: (i) regulatory risk (e.g., guaranteeing tariff adjustments by formula), (ii) compensation for competing facility, and (iii) payments arising from events of termination (government or concessionaire default, force majeure). Demand risk is assigned to the private sector, although there is flexibility through which the parties may agree to a minimum guaranteed demand.

Another awarded project, Modernization of Orthopedic Hospital, has been terminated by the winning bidder.

10 PPP Governing Board. 2016. Project appraisal. Policy Circular. No. 01A. Quezon City; PPP Governing Board. 2016. Value for money. Policy Circular. No. 09. Quezon City. 
Table 2: Risk Allocation for the Daang Hari Road Public-Private Partnership Concession (Build-Transfer-Operate Arrangement)

\begin{tabular}{|c|c|c|}
\hline Risk/Responsibility & Allocation & Rationale \\
\hline Demand Risk (Traffic) & Private Sector & Maximum traffic guarantee is not provided in the contract \\
\hline $\begin{array}{l}\text { Regulatory Risks (Toll and } \\
\text { Adjustment Implementation) }\end{array}$ & National Government & Tariff adjustment specified in the contract with private sector \\
\hline Project Financing & Private Sector & $\begin{array}{l}\text { Private Sector in controlof selecting and arranging long-term } \\
\text { financing (mix of local and foreign) }\end{array}$ \\
\hline Inflation and Foreign Exchange & Private Sector & $\begin{array}{l}\text { Private Sector in control of selecting and arranging long-term } \\
\text { financing (mix of local and foreign) }\end{array}$ \\
\hline $\begin{array}{l}\text { Basic ROW Acquisition and } \\
\text { Delivery }\end{array}$ & National Government & $\begin{array}{l}\text { Government has special powers of acquisition and use of } \\
\text { land }\end{array}$ \\
\hline Design/Construction & Private Sector & $\begin{array}{l}\text { Private Sector has control over the variables that determine } \\
\text { the quality of design and the contruction process. }\end{array}$ \\
\hline Operation/Maintenance & Private Sector & $\begin{array}{l}\text { Private Sector has control over the operation and } \\
\text { maintenance processes }\end{array}$ \\
\hline Political Risks & National Government & $\begin{array}{l}\text { Government is in better position to manage and mitigate } \\
\text { occurence of risk }\end{array}$ \\
\hline Force Majeure & $\begin{array}{l}\text { Both Private Sector and } \\
\text { National Government }\end{array}$ & $\begin{array}{l}\text { Private sector can buy insurance for insurable risks while } \\
\text { Government can assume uninsurable risks }\end{array}$ \\
\hline $\begin{array}{l}\text { Turn-over at the end of } \\
\text { Concession }\end{array}$ & Private Sector & Terms are included in the contract \\
\hline
\end{tabular}

Source(s): List table source(s).

\section{GOVERNMENT EXPOSURE UNDER PUBLIC-PRIVATE PARTNERSHIPS}

9. The government exposure from PPP projects arise from one of two sources: direct financial (viability gap fund [VGF] or availability payments) and nonfinancial costs (acquisition of right of way), and contingent liabilities. The DOF is responsible for the initial assessment of the fiscal impacts of these exposures as a long-term sustainability issue. Specifically, the DOF is expected to assess the suitability of the risk assignment and to determine the project's financial viability and the level of VGF and other forms of government support that may be required. This assessment includes estimating any potential availability payments and guarantees as well as the potential cost to government of contingent liabilities. In addition, the DOF is required to monitor the aggregate level of contingent liabilities to monitor the cumulative effect of these guarantees on fiscal sustainability. Within the DOF, the Corporate Affairs Group performs project level analysis and the Treasury and Debt and Risk Management Office monitors the aggregate level of contingent liabilities. A technical working group for contingent liability management has also been established to focus, initially, on drafting the implementing rules and regulations of the risk management program (Box 1).11

11 This working group is composed of DOF (Bureau of the Treasury, Corporate Affairs Group), Department of Budget and Management, Department of Public Works and Highways, Department of Transportation and Communication, and the PPP Center. 


\section{Box 1: Contingent Liabilities in Public-Private Partnerships}

Contingent liabilities are defined as payment obligations whose occurrence, timing, and amount depend on some uncertain future event or circumstance. Contingent liabilities are incurred when government (i) provides some form of assurance or guarantee for market risks; (ii) commits to a formula for tariffs which the Toll Regulatory Board could disallow or delay; (iii) commits to buyout the concessionaire and reimburse expenditures, projected returns, and repay financing if termination events occur; and (iv) commits to share in the cost of force majeure events which to the extent that these costs are not insurable.

Why manage contingent liabilities? (i) Control national government contingent exposures in PPP projects. Ensure that government is retaining the appropriate risk and there is meaningful transfer of risk to the private sector. (ii) Ensure that aggregate level of contingent liabilities is consistent with fiscal sustainability. (iii) Disclose the level and management process of contingent liabilities to credit rating agencies and investors, to support credit rating upgrade. (iv) Have in place a transparent and orderly process for disbursing or funding on contingent liability that have materialized.

Stakeholders' concerns: (i) Government might use contingent liabilities to "sidestep" standards for fiscal and financial prudence to engage in "stealth financing" in support of political objectives. (ii) Contingent liabilities allow execution of a number of major infrastructure projects at the same time (which would not have been possible within budget and borrowing ceilings). (iii) Contingent liabilities could accumulate to a level that could undermine fiscal sustainability should a number of these liabilities be realized at the same time. (iv) If there is no process for monitoring and disclosing the aggregate amount of outstanding contingent liabilities, the lack of transparency over such could affect overall investor confidence in the economy and assessments by credit rating agencies. ( $v$ ) If the provision for contingencies in the annual budget proves to be inadequate against liabilities that have materialized at a time when financial markets are volatile if not accessible, the funding of realized liabilities may have to be done under very disadvantageous terms.

Source: Lifted from selected slides in "Managing Contingent Liabilities in PPP Program," ADB

\section{PAYMENT GUARANTEES}

10. Payment guarantees pose a number of challenges. For direct liabilities, the problem is uncertainty due to the open-ended nature of a government's commitment to make available payments over time and protect investors from successive government changes over the life of the project. In recent projects, the Government of the Philippines used an instrument called a multiyear obligation authority to assure markets that the Department of Budget and Management will provide budget cover for the payments in succeeding budgets. However, investors have expressed discomfort with this authority because it commits the executive department but does not give assurance that Congress would approve the required amounts on an annual basis. An instrument that has been market tested but closely guarded (collateral damage from poorly-structured PPP projects in the past) is the performance undertaking, a confirmation note signed by the DOF secretary. This note provides a government performance guarantee on direct and contingent liabilities and carries the government's "full faith and credit." The government has taken the position that, at least for implementing line agencies which are departments of the national government, a performance undertaking is not needed. While the government is open to issuing such guarantees for projects of public corporations, the government has opted in one recent project to include a line department as cograntor (together with the government owned and controlled corporation).

11. For contingent liabilities, there is the added complication that the timing and amounts to be paid are uncertain. Hence, the multiyear obligation authority is not suitable. To assure investors that monies 
are available to pay for these contingencies if and when they arise, the government has established a P30 billion risk management program under the unprogrammed fund of the budget. The technical working group on contingent liabilities described in para. 8 has actually been tasked to oversee the risk management program through a set of implementing rules and regulations. However, these rules and regulations do not fully ensure that contingent liabilities are sovereign obligations to be automatically extinguished because the settlement of contingent liabilities is contingent on the availability of funds (nature of unprogrammed funds) and the Development Budget Coordinating Committee can exercise discretion over approving the payments. ${ }^{12}$

12. To address these issues, the government is considering the establishment of a revolving contingent liability fund (CLF) for PPP projects. This would represent a dedicated fund that will be built up over time from annual budgetary provisions based on the level of outstanding contingent liabilities. The CLF is part of the proposed amendments to the Build-Operate-Transfer Law and when established is expected to be supported by clear rules on (i) the definition and coverage of contingent liabilities; (ii) the measurement of contingent liabilities to determine the size of the CLF and related provisioning rules; (iii) management, risk mitigation, and payment rules; and (iv) recourse agreements for implementing agencies to reduce moral hazard. ${ }^{13}$ The latter may require implementing agencies to reimburse the CLF for any payouts, which means that implementing agencies would have to seek congressional approval for the payables.

\section{INTERNATIONAL BEST PRACTICES}

13. Public investment entails planning, budget allocation, and implementation. Efficient investment planning requires institutions that ensure public investment is fiscally sustainable and effectively coordinated across sectors, levels of government, and between public and private sectors. Allocation of capital spending to the most productive sectors and projects requires a comprehensive, unified, and medium-term perspective to capital budgeting, as well as objective criteria and competitive procedures for appraising and selecting particular investment projects. The timely and cost-effective implementation of public investment projects requires institutions that ensure projects are fully funded, transparently monitored, and effectively managed.

14. An appropriate framework includes a robust process to choose between public procurement and PPP for public infrastructure provision, recognizing that (i) the objectives of both modes of provision are the same (i.e., delivery of a public asset or services), and (ii) ultimately, funding will be sourced either from user charges or taxes. It bears emphasizing that PPPs "cannot make uneconomic projects viable nor can they finance unaffordable projects" and thus, should only be used when it can improve overall management and delivery of the project through the transfer of risks to the private sector. ${ }^{14}$

15. The case for using PPPs should be based on whether or not they deliver greater value for money to government. At the heart of PPPs is risk allocation based on the principle of assigning risks to the party best able to manage them. A well-structured PPP project involves the public sector transferring risks that the private sector can better absorb, with the efficiencies gained from private management of these risks translating into value for money for the public sector. Comparing the cost of government procurement and PPP should explicitly account for this risk assignment - the expected value of retained risks and how this affects government's overall cost following a whole-of-life, net present value valuation approach.

12 ADB. 2015. Strengthening Evaluation and Fiscal Cost Management of Public-Private Partnerships. Consultant's Report. Manila (TA 8650-PHI).

13 Footnote 12.

14 Footnote 12. 
16. A VFM analysis must reflect the difference in risk-adjusted cost for the government of delivering the project under each option. The objective of capturing all these costs right from the start is not just to allow government to make informed decisions about its risk exposures at the project level but to be able to put PPP projects alongside other publicly financed projects in planning and prioritizing public investments. These decisions - relating to how risks will be allocated, whether government needs to provide subsidies and in what form, and/or whether government should shoulder more risks-impact project outcomes and ultimately, cost to government.

17. Once the decision is taken to pursue a project through PPP, achieving value of money estimates requires government to continually manage the contingent liabilities arising from the project, over the life of the project, to minimize the risk of realizing contingent liabilities that would trigger payment clauses in the contract. Hence, a framework for managing contingent liabilities from PPPs needs to be in place. The system should not only manage risks at the project level but capture their aggregate impact on government's fiscal sustainability.

\section{KEY INSTITUTIONAL ISSUES}

\section{A. Budgeting, Planning, and Project Screening}

18. The Philippines has established a planning framework through the Philippine Development Plan. However, the plan does not specify costs and in practice, planning and budgeting are insufficiently linked. Given the size of the planned expansion in infrastructure spending, the government could achieve a significant increase in efficiency by improving coordination among central agencies and working through a medium-term planning framework that clearly identifies priority projects, guides the choice between the budget and PPP, and strengthens the link between planning and the budget. In addition, successful execution of a complex infrastructure development program requires a specific set of technical skills. Thus, it is crucial that the envisaged boost in the public infrastructure spending be accompanied by an intensive and continuing capacity development program within the concerned implementing agencies.

19. The Philippines has one of the largest PPP programs among emerging and advanced economies. ${ }^{15}$ Given persistent bottlenecks in various sectors, PPPs will remain an attractive option for meeting the infrastructure requirements of the economy. However, the large size of the Comprehensive and Integrated Infrastructure Program suggests that prioritization triggers could be strengthened to ensure the infrastructure program remains within the available resource envelope. To begin, a critical review of the stock of development projects could be undertaken to identify and remove projects that are no longer government priorities. Moreover, it is important to strengthen the gatekeeping role of NEDA and the ICC and to improve the ability of individual departments to appraise, prioritize, and select projects.

20. Finally, the current selection process, where PPP and non-PPP projects are separately reviewed and approved, suggests that PPP projects are not properly appraised within the medium-term public investment framework. ${ }^{16}$ Specifically, the government's guidelines require implementing agencies to select projects from the Philippine Investment Program (national level) or the Provincial Development Investment Program (local level) then use multicriteria analysis to assess PPP suitability. ${ }^{17}$ Projects that pass the multicriteria analysis undergo project preparation, supported by the PDMF or other sources

\footnotetext{
15 Johannes Mueller et al. 2015. Philippines: Fiscal Transparency Evaluation. IMF Country Report. No. 15/156. Washington, DC: IMF. p. 60.

16 Footnote 9.

17 PPP Governing Board. 2015. Identification, selection, prioritization. Policy Circular. No. 02. Quezon City.
} 
of funding, including an evaluation of their economic and financial viability and well as a risk analysis. ${ }^{18}$ Notwithstanding the resources devoted to PPP project preparation up to this point, not all the projects hurdle NEDA's socioeconomic review, pointing to inadequate filtering and creating inefficiencies in the use of government and PDMF resources.

21. Given that resources are finite, projects, regardless how financed, should be prioritized based on their economic and social returns. ${ }^{19}$ This practice might reflect a misperception that PPP's are a way to overcome budget constraints rather than as a way to tap private sector efficiencies to deliver VFM. To improve project selection and maximize the efficiency of public resources, the selection process could be improved to capture the full fiscal costs of PPPs through a systematic analysis and quantification of public sector risk over project life, together with any direct public costs. Such a quantification of the expected values of assumed risks will enable the government to properly evaluate and compare the provision of infrastructure projects through the available modalities: PPP or public funding.

22. The provision of subsidies. The government has a broad policy for accepting risks in PPP projects in GPRAM, but it could be more robust. Clear decision rules have been developed for granting subsidies (VGF), but the decision as to what risks to shoulder is less clear. ${ }^{20}$ In practice, the government's policy posture in recent years, intended to guard against a repeat of past realizations of contingent liabilities in PPP projects, has been "to be very selective to altogether avoid guaranteeing traffic demand and other risks which may be deemed noncore."21 This posture creates friction if the intention is to maximize the use of PPPs - and is especially problematic when contemplating economically desirable but complex greenfield projects that would benefit from private sector technical, management, and operational expertise but where government needs to share demand risk. In these cases, the government would benefit from a framework that explicitly considers whether shouldering specific noncore risks would maximize VFM without incurring high fiscal costs.

23. To support and expand this type of assessment, the current VFM analysis would need to be strengthened. Used appropriately, VFM translates future cash flows of public procurement and PPP into a single net present value for each option to facilitate decision making. Moreover, VFM analysis compels implementing agencies to think about project risks. ${ }^{22}$ To the extent that expected values of retained risks are properly calculated, the approach enables the cost of subsidies and retained risks to be captured in the PPP cashflows to ensure that ICC decisions are informed by the costs of risks assumed by government. ${ }^{23}$ Conversely, VFM analysis can help the government decide what risks to accept to maximize VFM in PPP projects. This analysis removes the temptation to saddle the public sector with more risks to make PPP projects bankable without consideration for the fiscal impact.

\section{B. Management of Contingent Liabilities}

24. The framework for managing contingent liabilities arising out of PPPs remains a work in progress. The most pressing need is to quantify the amount of existing contingent liability at the project level and aggregate level. In the past, consultants provided estimates of contingent liabilities from legacy PPP projects using probabilistic models that have been difficult to institutionalize in the DOF. Work is now ongoing to provide standard formulas and common assumptions for quantifying contingent liabilities

18 The PDMF is used to fund the development of a pipeline of PPP projects at the national and local levels.

19 Jorge Montecinos. 2016. Assessment of Contingent Liabilities from Public-Private Partnerships. Washington, DC: International Monetary Fund.

20 PPP Governing Board. 2015. Viability gap funding. Policy Circular. No. 04. Quezon City. This document prescribes that VGF will be available only for solicited projects which are economically viable but not financially attractive.

21 Footnote 6.

22 Government of the Philippines, PPP Center. National Government Agency Public-Private Partnership Manual vol. 1. Draft.

23 It is not clear how these risks are presently valued, albeit work is underway to develop risk valuation models. 
that will allow consistency across project and macro levels. The approach under development will analyze termination events and payout formulas based on project progress and specific project risk features. ${ }^{24}$

25. Sound management of contingent liabilities over the project cycle requires a number of elements. First, the government should have a thorough understanding of the nature of the accepted risks so that they can be accounted for properly, both on and off-budget, and the estimate values should be updated regularly as project and country conditions change. In this regard, a central database is useful to support monitoring, provisioning, and disclosure for transparency, and to assure credit markets that reliable payment mechanisms have been deployed to pay realized contingent liabilities, whether from line agencies or government-owned and controlled corporations, when due. ${ }^{25}$ In addition, robust monitoring systems are needed so that measures may be taken as appropriate. Finally, the budget should include provisions for the potential costs associated with contingent liabilities to reduce fiscal shocks.

26. As part of any management strategy, contingent liabilities should be treated as a scarce resource subject to prudential limits. Such a system would also include a hierarchical system of approvals to govern when contingent liabilities are accepted and for what reason. The adoption of aggregate, binding limits on all types of government exposures (VGF, availability payments, contingent liabilities) will ensure the government does not commit resources above what is fiscally affordable. A properly structured system of limits could include total aggregate public sector exposure to PPPs. In addition to annual flow limits, additional options include stock limits on the overall size of the PPP program or total project liabilities as part of an overall debt management strategy.

27. In addition, a formal management plan should be developed for implementing agencies to use in monitoring project risks over project life and for the DOF to perform effective oversight and risk mitigation. The plan should clearly identify the processes for resolving disputes and contract breaches that would trigger government payments, including the processes and procedures for settling events of termination from the time default clauses are triggered to the payment of just compensation. Implementing agencies should also be required to share this risk and be held accountable for the failure to perform under the contracts that eventually lead to the payout on contingent liabilities.

28. The existing PPP contract structure could be clarified to reduce uncertainty surrounding early termination. The current policy is skewed toward the concessionaires and leaves some ambiguity regarding the conditions necessary to declare an early termination, the steps to be taken after the decision, and the amount of compensation that needs to be addressed. In particular, the phrase "all actions possible" that must be exhausted before termination should be more clearly defined, procedures should be expressly stipulated, and the responsibilities of each relevant party after the early termination should be established.

24 Concerning government payouts in the event of concessionaire default, there is a need to review relevant clauses in the concession agreements to ensure that incentives are in place for creditors to conduct their due diligence of project risks independent of any government commitment to make them whole.

25 Government of the Philippines, Department of Budget and Management. 2015. Fiscal Risks Statement 2015-2016. Manila. In its annual statement, government reports estimated contingent liability stock based on the maximum exposure under 10 projects awarded under the Aquino Administration plus the total project cost of 69 legacy projects (p. 48). It also includes a potential budget outflow estimate of $0.14 \%$ of GDP without identifying the basis for the valuation. 


\section{Accounting Treatment}

29. To ensure transparency and to strengthen analysis, direct and contingent costs should be recorded on an equivalent basis to provide for comparisons of projects supported by PPPs or with public procurement. In addition, the accounting treatment of some PPP projects indicates there may have not been sufficient risk transfer to the private sector. These projects may be considered financial leases rather than contingent liabilities, requiring government to recognize all the liabilities upfront and expense as they are accrued (e.g., the two classrooms project). More generally, the accounting treatment of all PPP projects should be consistent with international accounting standards (e.g., International Public Sector Accounting Standards). ${ }^{26}$

\section{Technical Bidding Matters}

30. The recent experience with aggressive bid outcomes reveals that fiscal risks in PPPs have been offset to an extent by fiscal windfalls. In several of the large projects that used "lowest VGF" as bid parameter, private bidders revealed their willingness to instead pay government premiums for the right to undertake the projects. This is due largely to the synergies created with the proponents' other lines of business. Critics have argued that these windfalls were at the expense of consumers, and government should instead use "lowest tariff" as the bid parameter to maximize the project's economic benefits. As government has no way of knowing in advance how bidders' private interests would affect their required project returns, the proposed solution, in cases where bidders do not require subsidies (VGF), is to require them to simply submit a bid tariff; winners are then chosen on the basis of "lowest tariff."

\section{OTHER INSTITUTIONAL AND LEGAL ISSUES}

31. Developing the institutional, technical, legal, and financial capacity for PPPs, both at the level of oversight and implementing agencies, is a work in progress, although progress has been uneven in a number of agencies. Strengthened capacity at the level of implementing agencies can reduce the current reliance on the PPP Center and the PDMF for pipeline development. In addition, there is a need to develop clearer sector plans in order to improve project identification and selection given the government's limited budget resources.

32. Regulatory institutions should be headed by nonpolitical leadership, with strengthened capacity and provided with a deep bench of independent career professionals. Regulatory inconsistencies that typically accompany changes in government create uncertainties. Contract disputes (e.g., Manila's water concession, Ninoy Aquino International Airport Terminal 3) and recalled biddings (e.g., Cavite-Laguna Expressway) have heightened investors' unease and increase risk premiums for project finance.

33. Amending the 20-year old Build-Operate-Transfer Law is long overdue. A number of changes have been proposed and include (i) improving the transparency of PPP structures by covering joint venture arrangements; (ii) removing the $50 \%$ cap on government participation which has not proven effective in limiting government exposures; (iii) strengthening the unsolicited proposal track, including enhancing competition for Swiss Challenge under unsolicited proposals (extending the period for preparation of competing bids); (iv) institutionalizing financial support measures, including the PDMF and setting up a CLF, and; (v) institutionalizing the PPP Center and its governance structure.

26 Footnotes 6 and 19. 
34. Amending the Constitution, Regular Foreign Investment Negative List and other laws such as redefining public utilities to ease legal restrictions on foreign investments in infrastructure should also be considered to attract more investments from diverse sources. This will help expand the pool of funding sources, given the limited number of domestic conglomerate-investors, and augment funding in case of an economic downturn that reduces local sources. These changes would also increase competition during the bidding process and improve efficiency in bid preparation, project design, and execution. ${ }^{27}$

35. Until recently, the main cause of construction delays in PPP projects was the failure to secure right-of-way in a timely manner. The Right-of-Way Act, enacted in 2016, seeks to facilitate rightof-way acquisition. Among other features, the new law specifies a formula for the compensation price, provides for specific timelines for expropriation proceedings, and for PPP projects, allows the project proponent to advance the cost which will be repaid out of agency budgets or recovered from tariffs. The effectiveness has yet to be tested but market feedback about the provisions has been positive.

\section{Box 2: Unsolicited Proposal Issues}

What: These are private sector-initiated projects proposed to be undertaken under the Build-OperateTransfer (BOT) Law. Proposals must meet the following conditions: (i) the project involves a new concept or technology and/or is not part of the list of government's list of priority projects; (ii) the project does not require direct government guarantee, subsidy or equity; and (iii) the government agency has invited comparative or competitive proposals and no complying bid is received after 60 days. If a complying bid is received within 60 days, the original proponent has the right to match.

Issues: In the past, "most of the controversial infrastructure projects in the Philippines started as unsolicited proposals," with the World Bank reporting a number of scandals that included the Ninoy Aquino International Airport terminal 3 and the Caliraya-Botocan-Kalayaan (CBK) hydroelectric power BOT projects. While the implementing rules and regulations (IRRs) require that all unsolicited proposals go through the Investment Coordination Committee (ICC), "proponents of unsolicited proposals have bypassed the ICC, and instead, directly sought the approval of the Office of the President. The vagueness of the law and IRR at that time also allowed unsolicited proposals to obtain some form of indirect guarantees. There was also lack of clarity in the definition of government guarantees and the role of implementing agencies in contract revisions" (Policy Paper-Philippine Guarantees and Contingent Liability Review, para. 62). Project debt of unsolicited projects should not be subject to the "terminal clause" that effectively guarantees senior debt of the project in the event of concessionaire default, except in cases where the government clearly wants to bear the project financing risks in the public interest.

Recent developments: There has been a policy preference for the solicited route under the Aquino administration. The 2012 amendment to the IRRs clarified that right-of-way cost as constituting a subsidy and thus, for unsolicited proposals would require that government be compensated for the cost.

Proposed changes to BOT Law (House Bill 3951): The changes will enhance competition for Swiss Challenge under unsolicited proposals by extending the period for preparation of competing bids to 6 months and will provide implementing agencies different options for dealing with unsolicited proposals, including using the proposal as basis for public bidding subject to reimbursement of development cost incurred.

27 Footnote 2. 


\section{POLICY RECOMMENDATIONS}

36. This working paper provides the following recommendations:

(i) Improve the planning process by undertaking a critical review of the stock of development projects to eliminate duplications, unnecessary projects, and projects that are no longer priorities for the government.

(ii) Strengthen the links between planning and budgeting by anchoring planning within an overall medium-term resource framework and improving the coordination among high level structures, including the Department of Budget and Management, NEDA, ICC, and Executive Technical Board.

(iii) Develop and strengthen department and agency processes for identification, appraisal, prioritization, and selection of project proposals. The revised processes should emphasize that the decisions on which projects to include should be based on the medium-term resource ceiling.

(iv) Improve comprehensiveness of capital expenditures in the budget through strengthening the gatekeeping role (e.g., NEDA board, ICC) for inclusion of projects in the budget.

(v) Strengthen further the linkage between the PPP program and government's medium-term public investment plan to ensure that PPP projects are appraised and selected alongside publicly financed projects, constrained by available fiscal resources.

(vi) Strengthen VFM analysis to ensure that decision makers are fully informed of the cost of public sector risks under PPPs when comparing this financing option against public procurement. The VFM must reflect the difference in (risk-adjusted) cost for the government of delivering the project under each option.

(vii) On contingent liabilities, government should have (a) a clear policy on accepting risks in PPPs based on maximizing VFM while controlling for fiscal costs, (b) quantify the costs of accepted risks based on expected values using standard formulas and common assumptions that would allow consistency in treatments at the project and macro level, and (c) put in place a contingent liability management framework at the project and macro level that allows (i) contingent liabilities to be identified, quantified, and continually monitored, risks mitigated, exposures disclosed and realized contingent liabilities paid for (following clear procedures in case of termination events); and (ii) clear delineation of responsibilities between implementing and oversight agencies (particularly DOF) and coordination mechanisms.

(viii) Clarify the process of early termination policy further. In particular, define "all actions possible" that must be exhausted before termination more clearly, and establish a clear procedure and roles and responsibilities of each relevant party after the early termination.

(ix) Consider setting a budget for contingent liabilities, either stock or flow or both, to have limit excessive risk taking in PPP projects.

(x) It might be of interest to undertake a public investment management assessment for a comprehensive assessment of the public investment decision-making process in planning, budget allocation, and implementation. 
(xi) Continue to develop capability of implementing agencies for sector planning and project development.

(xii) Continue to improve government's accounting and budgeting, working toward institutionalizing accrual accounting and a medium-term expenditure framework to allow PPP projects to be accounted for and reported in accordance with international accounting standards. As a first step, consider projects that may involve insufficient risk transfer to be recognized in government's balance sheet.

(xiii) Amend relevant laws to further improve the legal and regulatory environment for PPP and to attract more investors into infrastructure. 


\section{Scaling Up Infrastructure Investment in the Philippines Role of Public-Private Partnership and Issues}

This publication analyzes public-private partnership (PPP) arrangements in the Philippines and their critical role in increasing infrastructure investment requirements. It looks into the Philippine experience of embarking on PPP modality from various dimensions and points out key challenges that will need to be overcome. In this publication, you will also learn more about policy recommendations for the government to mobilize private sector expertise and resources to improve PPP project screening, approvals, and implementation.

\section{About the Asian Development Bank}

ADB's vision is an Asia and Pacific region free of poverty. Its mission is to help its developing member countries reduce poverty and improve the quality of life of their people. Despite the region's many successes, it remains home to a large share of the world's poor. ADB is committed to reducing poverty through inclusive economic growth, environmentally sustainable growth, and regional integration.

Based in Manila, ADB is owned by 67 members, including 48 from the region. Its main instruments for helping its developing member countries are policy dialogue, loans, equity investments, guarantees, grants, and technical assistance. 